\title{
Esophageal schwannoma
}

\author{
A. Basoglu, MD, ${ }^{a}$ B. Celik, MD, ${ }^{a}$ T. A. Sengul, MD, and L. Yildiz, MD, ${ }^{\text {b }}$ Samsun, Turkey
}

$\mathrm{N}$ eurogenic tumors are the most common primary tumors of the mediastinum, and schwannomas are the most common neurogenic tumors of the mediastinum, accounting for $8 \%$ of all mediastinal tumors. ${ }^{1}$ However, they are extremely rare in the esophagus. Chatelin and Fissore $^{2}$ first reported this entity in 1967 , and a few cases have been presented in the literature. We report an extremely rare case of esophageal schwannoma.

\section{Clinical Summary}

A 54-year-old woman was admitted to our hospital with a 2-year history of dysphagia, a mass on the left side of her neck, and weight loss. On physical examination, there was a swelling on the left side of her neck. Chest radiography demonstrated an abnormal shadow in the upper mediastinum. The barium esophagogram showed a tumor that was $7 \mathrm{~cm}$ in size in the upper thoracic esophagus (Figure 1, A,B).

From the Departments of Thoracic Surgery ${ }^{\mathrm{a}}$ and Pathology, ${ }^{\mathrm{b}}$ Ondokuz Mayıs University, Medical School, Samsun, Turkey.

Received for publication July 6, 2005; accepted for publication Sept 9, 2005.

Address for reprints: Ahmet Basoglu, Ondokuz Mayıs University Medical School, Department of Thoracic Surgery, 55139 Kurupelit, Samsun, Turkey (E-mail: ahmetb@omu.edu.tr).

J Thorac Cardiovasc Surg 2006;131:493-5

$0022-5223 / \$ 32.00$

Copyright (C) 2006 by The American Association for Thoracic Surgery doi:10.1016/j.jtcvs.2005.09.020
Chest computed tomography revealed a solid mass in the upper one third of the esophagus, which surrounded the lumen (Figure 1, $C, D)$. Esophagoscopy showed a submucosal tumor without mucosal lesion located 15 to $21 \mathrm{~cm}$ from the incisors.

At exploration, there was a mass $6 \times 6 \mathrm{~cm}$ in size located over the cervical esophagus. A frozen section showed the mass to be a malignant lesion. Subtotal esophagectomy and esophagogastrostomy were performed through the abdominocervical approach. The postoperative course was uneventful. The patient was discharged on the 12th postoperative day. The patient has been doing well with no recurrence at 40 months after the operation.

The pathologic diagnosis was esophageal schwannoma with malignant degeneration. On microscopic examination, we observed spindle tumor cells under esophageal epithelium. The tumor contained rare pleomorphic cells and few mitotic figures and invaded the serosal surface of the esophagus (Figure 2). There was no necrosis in the tumoral areas. Tumor cells were S-100 and vimentin positive and smooth muscle actin, CD117, and CD34 negative in immunohistochemical method.

\section{Discussion}

The majority of esophageal malignancies are either squamous cell carcinomas or adenocarcinomas. In rare instances a malignant tumor arising in the esophagus does not resemble one of these 2 common cell types, such as a schwannoma.

Schwannomas are peripheral nerve sheath tumors and can arise in any nerve in which Schwann cells occur, although schwannomas are most commonly found in the head, neck, or extremities.
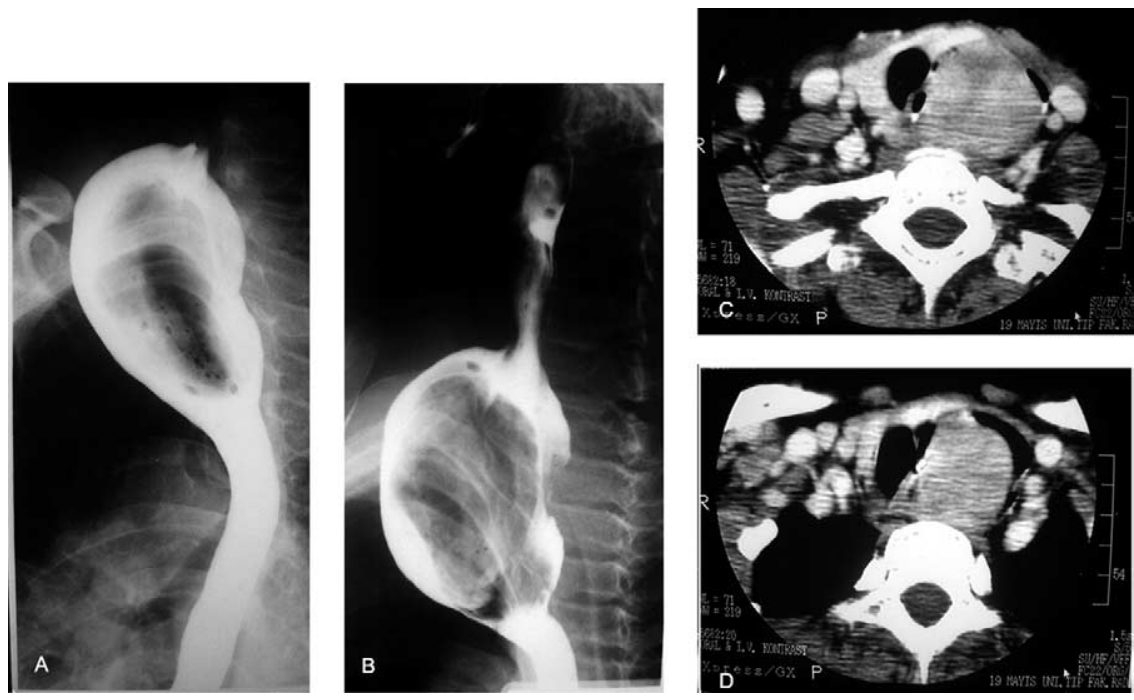

Figure 1. A, B, The barium esophagogram showed a tumor in the upper thoracic esophagus. C, D, Chest computed tomography showed a solid mass in the upper thoracic esophagus. 

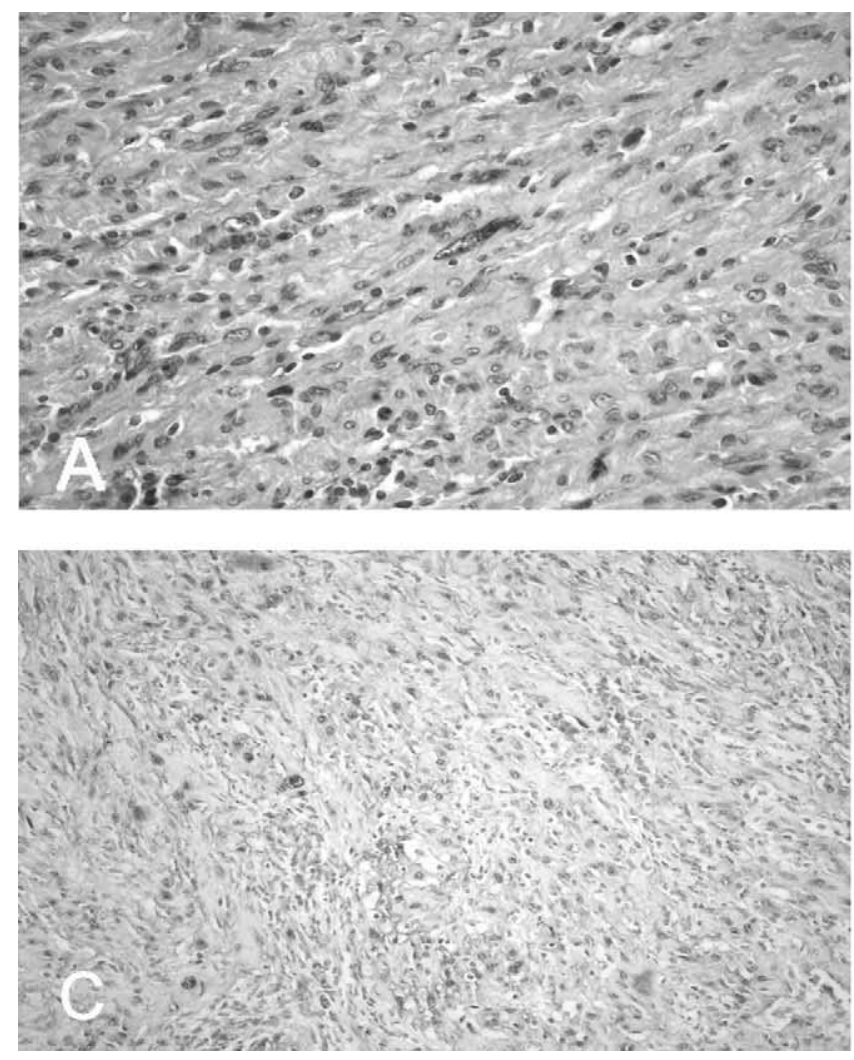

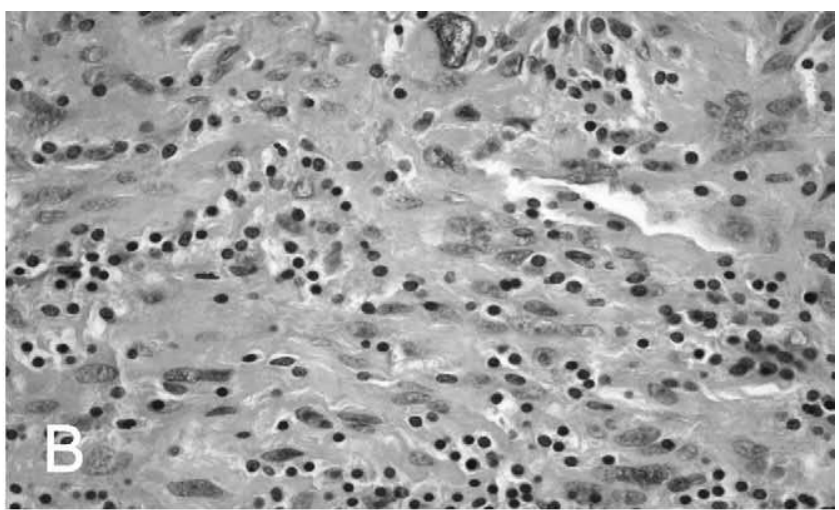

Figure 2. A, Spindle pleomorphic tumoral cells. (hematoxylin and eosin stain, original magnification $200 \times$.) B, Spindle pleomorphic tumoral cells. (hematoxylin and eosin stain, original magnification $400 \times$.) C, S-100 positivity in tumor cells. (biotin-streptavidin, Diaminobenzidine chromogen; original magnification $200 \times$.)
They can develop within the chest, where they usually originate in the posterior mediastinum. ${ }^{3}$ They are extremely rare in the esophagus.

Review of the previous reports indicates that schwannomas are usually located in the upper esophagus and occur frequently in middle-aged women, as in our case. There were no distinctive characteristics from other submucosal tumors, and therefore the differentiation of schwannomas from the other submucosal tumors is very difficult on preoperative and perioperative examination. Most submucosal tumors of the esophagus are leiomyomas, cysts, or lipomas. ${ }^{4}$ The treatment is resection, both for removing the tumor and for diagnosis. Correct diagnosis of the tumor requires a histologic examination. Positive immunostaining for S-100 protein supports the Schwann cell origin of the tumor. ${ }^{4}$

Generally, the prognosis of schwannoma is excellent. However, 3 cases with malignant findings and one case with local recurrence were reported. ${ }^{1,5}$ If malignant histology is found, the patient must be followed up for a prolonged period after the operation. Our patient has been doing well, with no recurrence at 40 months after the operation. Although rare, schwannomas should be included in differential diagnosis of esophageal submucosal tumors.

\section{References}

1. Iwata H, Kataoka M, Yamakawa Y, Kuwabara Y, Kureyama Y, Masaoka A. Esophageal schwannoma. Ann Thorac Surg. 1993;56: 376-7.

2. Chatelin CL, Fissore A. Schwanome degenere de l'esophage. Confront Radio Anat Clin. 1967;7:114.

3. Heitmiller RF, Labs JD, Lipsett PA. Vagal schwannoma. Ann Thorac Surg. 1990;50:811-3.

4. Stefansson K, Wollmann R, Jerkovic M. S-100 protein in soft-tissue tumors derived from Schwann cells and melanocytes. Am J Pathol. 1982;106:261-8.

5. Morita I, Mushiaki H, Shinozaki Y, et al. A case of the esophageal submucosal schwannoma with pathological malignant finding [in Japanese]. Geka. 1996;58:506-10. 